\title{
Pengaruh Lingkungan Kerja, Stres Kerja, Pengawasan terhadap Semangat Kerja Karyawan (Studi pada CV. Bintang Tex Indonesia- Tulangan Sidoarjo)
}

\author{
*Nafalina Sitta Dewi, Siti Rosyafah, Indah Noviandari \\ Prodi Manajemen Fakultas Ekonomi dan Bisnis Universitas Bhayangkara, Indonesia
}

DOI: 10.46821/benchmark.v1i2.141

\begin{abstract}
Abstrak
Ada beberapa faktor yang dapat mempengaruhi semangat kerja karyawan antara lain: lingkungan kerja, stres kerja dan pengawasan. Penelitian ini bertujuan untuk mengetahui dan membuktikan pengaruh lingkungan kerja, stres kerja, pengawasan terhadap semangat kerja karyawan (studi pada CV. Bintang Tex Indonesia-Tulangan Sidoarjo), secara simultan maupun parsial. Hasil penelitian menunjukan bahwa: lingkungan kerja, stress kerja dan pengawasan berpengaruh positif terhadap semangat kerja hal ini dibuktikan dengan nilai Fhitung > Ftabel $(109.945>2,76)$ dan nilai signifikansi Fhitung sebesar 0,000. Lingkungan kerja berpengaruh positif terhadap semangat kerja hal ini dibuktikan dengan nilai thitung $>$ ttabel $(9.507>2.003)$ dan nilai signifikansi sebesar $0,000<0,05$, stress kerja berpengaruh negative terhadap semangat kerja hal ini dibuktikan dengan nilai thitung $>$ ttabel $(-3.183>$ 2.003) dan nilai signifikansi sebesar 0,002 <0,05, pengawasan berpengaruh positif terhadap semangat kerja hal ini dibuktikan dengan nilai thitung $>$ ttabel $(3.276>2.003)$ dan nilai signifikansi sebesar $0,002<0,05$. Lingkungan Kerja berpengaruh secara dominan terhadap Semangat Kerja Karyawan, hal ini dibuktikan oleh besarnya nilai 0,701 pada hasil pengujian parsial (uji t) nilai beta tertinggi.
\end{abstract}

Kata kunci : Lingkungan Kerja, Stres Kerja, Pengawasan dan Semangat Kerja Karyawan

\begin{abstract}
There are several factors that can affect Employee Spirit Of Work: work environment, work stress and supervision. This study aims to determine and prove Effect OfWork Environment, Work Stress, Supervision Against Employee Spirit Of Work (Study In CV. Bintang Tex Indonesia-Tulangan Sidoarjo), simultaneously or partially. The results showed that: work environment, work stress and supervision had a positive effect on morale. This was evidenced by the value of Fcount $>$ Ftable $(109,945>2.76)$ and the significance value of Fcount of 0,000 . The work environment has a positive effect on morale, this is evidenced by the value of tcount $>$ ttable $(9.507>2.003)$ and a significance value of $0.000<0.05$, work stress has a negative effect on morale, this is evidenced by tcount $>$ ttable $(-3.183>2.003)$ and a significance value of $0.002<0.05$, supervision has a positive effect on morale, this is evidenced by the tcount $>$ ttable $(3,276>2,003)$ and a significance value of $0.002<0.05$. The Work Environment has a dominant influence on the Employee Spirit, this is evidenced by the value of 0.701 on the results of partial testing ( $t$ test) the highest beta value.
\end{abstract}

Keywords: Work Environment, Work Stress, Supervision and Employee Spirit of Work

*Corresponding Author:

Hal: 40-48

Email: nafa.sitta@gmail.com 


\section{PENDAHULUAN}

Di era Globalisasi saat ini dan perkembangan perekonomian dunia yangsemakin maju dan modern, sehingga persaingan diantara para pengusaha juga semakin ketat,masing masing perusahaan berusaha meningkatkan kualitas sumber daya manusia dan meningkatkan segala aspek .Sumber Daya Manusia (SDM) adalah faktor penting dalam suatu perusahaan, karena sumber daya manusia adalah kumpulan dari sekelompok orang-orang yang bekerja sama untuk mencapai tujuan tertentu.CV. Bintang Tex Indonesia merupakan perusahaan yang beroperasi pada bidang tekstil.Memproduksi benang, yang di distribusikan ke berbagai daerah seperti Sidoarjo, Surabaya, Gresik, Lamongan, Madiun, Ngawi dan Nganjuk.Mengingat pentingnya peranan karyawan dalam menjalankan aktivitas perusahaan, pihak manajemen perusahaan dituntut untuk memperhatikan dengan sungguh-sungguhtenaga kerjanya agar semangat kerja karyawan meningkat.

Menurut Anaroga dalam Busro (2018:327), faktor yang mempengaruhi semangat kerja adalah kondisi kerja yang menyenangkan. Suasana lingkungan kerja yang harmonis, tidak tegang, merupakan syarat bagi timbulnya semangat kerja.Lingkungan fisik yang bersih, rapi, asli, akan mampu meningkatkan semangat kerja.

Selain faktor lingkungan kerja adalah dikarenakan faktor stres kerja.Stres juga memiliki dampak yang negatif terhadap keadaan psikologis dan biologis bagi karyawan. Stres kerja dapat disebabkan oleh masalah dalam perusahaan, masalah dalam perusahaan tersebut salah satunya adalah konflik antar pribadi atau juga bisa berbagai bentuk konflik dalam perusahaan tersebut.

Selain itu Faktor pengawasan dapat mempengaruhi semangat kerja, Perusahaan sangat memerlukan pengawasan untuk mencapai tercapainya tujuan. Pengawasan yang berlebihan akan mematikan kreativitas, dan sebagainya yang akhirnya merugikan perusahaan, Busro (2018:144).

\section{TINJAUAN PUSTAKA}

\section{Pengertian Lingkungan Kerja}

Menurut Mardiana dalam Sudaryo (2018:47), lingkungan kerja adalah lingkungan dimana pegawai melakukan pekerjaannya sehari-hari.

\section{Indikator Lingkungan Kerja}

Menurut Sudaryo (2018:51), secara umum menyebutkan beberapa aspek dalam indikator lingkungan kerja yaitu:

1. Penerangan

2. Pewarnaan

3. Kebersihan

4. Pertukaran udara

5. Suara/kebisingan

6. keamanan

\section{Pengertian Stres Kerja}

Menurut Cary Cooper dan Alison Straw dalam Riinawati (2019:104), stress adalah tekanan, ketegangan, atau gangguan yang tidak menyenangkan yang berasal dari luar diri seseorang. 
Indikator-Indikator Stres Kerja

Menurut Sinambela (2016:473), indikator-indikator penyebab stres yaitu:

1. Beban kerja yang dirasakan terlalu berat

2. Waktu kerja yang mendesak

3. Kualitas pengawasan kerja yang rendah

4. Iklim kerja yang tidak sehat

5. Sikap pemimpin

\section{Pengertian Pengawasan}

Menurut Terry dan Leslie dalam Gavinov (2016:115), pengawasan adalah proses pengevaluasikan pelaksanaan kerja dengan membandingkan pelaksanaan kerja dengan membandingkan pelaksanaan aktual dengan apa yang diharapkan serta mengambil tindakan yang perlu.

\section{Indikator-Indikator Pengawasan}

Menurut Siregar (2017:21) indikator pengawasan yaitu:

1. Akurat

2. Tepat waktu

3. Obyektif dan menyeluruh

4. Terpusat pada titik-titik pengawasan strategi

\section{Pengertian Semangat Kerja}

Menurut Anaroga dalam Busro (2018:326), semangat kerja adalah suasana batin untuk melakukan pekerjaan secara lebih giat sehingga pekerjaan cepat selesai dan lebih baik serta ongkos per unit dapat diperkecil.

\section{Indikator-Indikator Semangat Kerja}

Menurut Tohardi dalam Syaputra (2017:16), indikator semangat kerja yaitu:

1. Rendahnya ProduktivitasKerja

2. Tingkat Absensi Yang Tinggi

3. Labour turn over atau tingkat perpindahan karyawan yang tinggi

4. Tingkat Kerusakan yang Meningkat

5. Kegelisahan Dimana -mana

6. Tuntutan yang Sering Terjadi

7. Pemogokan-Pemogokan

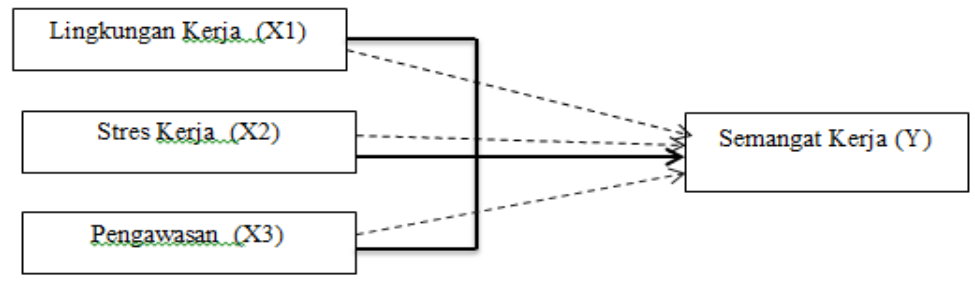

Sumber: Peneliti (2020)

Gambar 2

Kerangka Konseptual 


\section{Hipotesis}

a. Bahwa variabel lingkungan kerja, stress kerja, dan pengawasanberpengaruh secara simultan dan signifikan terhadap variabel semangat kerja karyawan (studi pada CV. Bintang Tex Indonesia-Tulangan Sidoarjo).

b. Bahwa variabel lingkungan kerja, stress kerja, dan pengawasan berpengaruh secara parsial dan signifikan terhadap variabel semangat kerja karyawan (studi pada CV. Bintang Tex Indonesia-Tulangan Sidoarjo).

c. Bahwa variabel lingkungan kerja berpengaruh dominan terhadap semangat kerja karyawan (studi pada CV. Bintang Tex Indonesia-Tulangan Sidoarjo).

\section{METODE PENELITIAN}

\section{Populasi}

Populasi dalam penelitian ini adalah karyawan CV. Bintang Tex Indonesia yang sejumlah 60 karyawan.

\section{Sampel}

Mengingat jumlah populasi 60 karyawan maka menggunakan sampling jenuh sehingga menggunakan seluruh sampel.

\section{HASIL ANALISIS DAN PEMBAHASAN}

\section{Uji Validitas}

Berdasarkan table diatas menunjukkan bahwa semua indikator dari variabel yang dgunakan dalam penelitian ini semuanya valid karena memiliki nilai rhitunglebih dari $r$ tabel sebesar 0,2542 .

\section{Uji Reliabilitas}

Berdasarkan tabel 2 dapat diketahui bahwa hasil Cronbach Alpha setiap variabel lebih dari standar Cronbach Alpha yang disyaratkan yaitu 0,70. Maka variabel Lingkungan Kerja, Stres Kerja, Pengawasan dan Semangat Kerja reliabel, semua pernyataan memiliki tingkat keandalan yang baik dan dapat digunakan dalam analisis penelitian ini.

\section{Analisis Regresi Linear Berganda}

Berdasarkan tabel di atas diperoleh persamaan regresi berganda sebagai berikut:

$\mathrm{Y}=1,105+0,621 \mathrm{X} 1-0,147 \mathrm{X} 2+0,240 \mathrm{X} 3$

Keterangan :

$\mathrm{Y}=$ Semangat Kerja Karyawan

$\mathrm{X} 1=$ Lingkungan Kerja

$\mathrm{X} 2=$ Stres Kerja

$\mathrm{X} 3=$ Pengawasan

Penjelasan dari persamaan diatas adalah sebagai berikut:

a. Konstanta $(\beta 0)$ senilai 1.105 yang menunjukan bahwa besarnya pengaruh variabel bebas terhadap variabel terikat, dimana apabila variabel bebas $=0$ maka nilai dari semangat kerja karyawan sebesar 1.105. 
b. Nilai konstanta regresi variabel lingkungan kerja ( $\beta 1$ ) sebesar 0,621dengan arah positif menunjukan bahwa lingkungan kerja meningkat satu-satuan maka akan meningkatkan semangat kerja karyawan sebesar 0,621 satuan dengan asumsi variabel lain konsta.

c. Nilai konstanta regresi variabel stress kerja ( $\beta 2)$ sebesar -0,147 dengan arah negative menunjukan bahwa stress kerja meningkat satu-satuan maka akan menurunkan semangat kerja karyawan sebesar -0,147 satuan dengan asumsi variabel lain konsta.

d. Nilai konstanta regresi variabel pengawasan ( $\beta 3$ ) sebesar 0,240 dengan arah positif menunjukan bahwa pengawasan meningkat satu-satuan maka akan meningkatkan semangat kerja karyawan sebesar 0,240 satuan dengan asumsi variabel lain konsta.

\section{Uji Simultan (Uji F)}

Berdasarkan tabel 4 dapat diketahui bahwa nilai $\mathrm{F}$ hitung sebesar 109.945 sedangkan $\mathrm{F}$ tabel (dengan tingkat kepercayaan $\alpha$ sebesar 0,05 derajat bebas regresi sebesar 3 dan derajat residualnya 56) adalah sebesar 2,76 karena Fhitung lebih besar dari Ftabel maka H0 ditolak dan H1 diterima, dengan tingkat signifikan sebesar 0,000 lebih kecil dari 0,05, sehingga dapat disimpulkan bahwa variabel bebas lingkungan kerja (X1), stress kerja (X2), pengawasan (X3), secara simultan berpengaruh signifikan terhadap variabel terikatnya yaitu semangat kerja karyawan (Y).

\section{Tabel 1}

\section{Hasil Perhitungan Uji Validitas}

\begin{tabular}{|c|c|c|c|c|c|}
\hline Variabel & Indikator & R hitung & Tanda & $\mathrm{R}$ tabel & Keterangan \\
\hline \multirow{3}{*}{$\begin{array}{l}\text { Lingkungan Kerja } \\
\text { (X1) }\end{array}$} & Kebersihan (X1.1) & 0,822 & $>$ & 0,2542 & Valid \\
\hline & Pertukaran Udara (X1.2) & 0,492 & $>$ & 0,2542 & Valid \\
\hline & Suara/Kebisingan (X1.3) & 0,840 & $>$ & 0,2542 & Valid \\
\hline \multirow{3}{*}{ Stres Kerja (X2) } & $\begin{array}{c}\text { Beban kerja yang dirasakan terlalu } \\
\text { berat (X2.1) }\end{array}$ & 0,712 & $>$ & 0,2542 & Valid \\
\hline & Waktu kerja yang mendesak (X2.2) & 0,828 & > & 0,2542 & Valid \\
\hline & Iklim kerja yang tidaksehat (X2.3) & 0,849 & $>$ & 0,2542 & Valid \\
\hline \multirow{3}{*}{ Pengawasan (X3) } & Tepat waktu (X3.1) & 0,775 & $>$ & 0,2542 & Valid \\
\hline & Obyektif dan menyeluruh (X3.2) & 0,422 & $>$ & 0,2542 & Valid \\
\hline & $\begin{array}{c}\text { Terpusat pada titik-titik } \\
\text { pengawasan strategi (X3.3) }\end{array}$ & 0,814 & $>$ & 0,2542 & Valid \\
\hline \multirow{5}{*}{ Semangat Kerja (Y) } & Rendahnya produktivitas kerja (Y1) & 0,779 & $>$ & 0,2542 & Valid \\
\hline & Tingkat absensi yang tinggi (Y2) & 0,512 & $>$ & 0,2542 & Valid \\
\hline & $\begin{array}{c}\text { Tingkat perpindahan karyawan } \\
\text { yang tinggi (Y3) }\end{array}$ & 0,746 & $>$ & 0,2542 & Valid \\
\hline & Kegelisahan dimana mana (Y4) & 0,512 & $>$ & 0,2542 & Valid \\
\hline & Tuntutan yang sering teriadi (Y5) & 0,573 & $>$ & 0,2542 & Valid \\
\hline
\end{tabular}

Sumber: Peneliti 2020 


\section{Tabel 2}

Hasil Perhitungan Uji Reliabilitas

\begin{tabular}{|c|l|c|c|c|c|}
\hline No & Variabel & $\begin{array}{c}\text { Cronbach's } \\
\text { Alpha }\end{array}$ & Tanda & $\begin{array}{c}\text { Minimal } \\
\text { Cronbach's } \\
\text { Alpha yang } \\
\text { Disyaratkan }\end{array}$ & Keterangan \\
\hline 1 & Lingkungan Kerja (X1) & 0,841 & $>$ & 0,70 & Reliabel \\
\hline 2 & Stres Kerja (X2) & 0,894 & $>$ & 0,70 & Reliabel \\
\hline 3 & Pengawasan (X3) & 0,808 & $>$ & 0,70 & Reliabel \\
\hline 4 & Semangat Kerja (Y) & 0,827 & $>$ & 0,70 & Reliabel \\
\hline
\end{tabular}

Sumber: Peneliti 2020

Tabel 3

Analisis Regresi Linear Berganda

\begin{tabular}{|c|l|r|r|r|r|r|}
\hline \multicolumn{2}{|l|}{ Model } & \multicolumn{2}{c|}{$\begin{array}{c}\text { Unstandardized } \\
\text { Coefficients }\end{array}$} & $\begin{array}{c}\text { Standardized } \\
\text { Coefficients }\end{array}$ & \multirow{2}{*}{ Sig. } & \\
\cline { 3 - 7 } \multicolumn{2}{c|}{} & \multicolumn{1}{|c|}{ B } & Std. Error & Beta & & \\
\hline \multirow{2}{*}{1} & (Constant) & 1.105 & .274 & & 4.038 & .000 \\
\cline { 2 - 7 } & Lingkungan Kerja (X1) & .621 & .065 & .701 & 9.507 & .000 \\
\cline { 2 - 7 } & Stres Kerja (X2) & -.147 & .046 & -.164 & -3.183 & .002 \\
\cline { 2 - 7 } & Pengawasan (X3) & .240 & .073 & .240 & 3.276 & .002 \\
\hline
\end{tabular}

Sumber: Peneliti 2020

Tabel 4

UJI F

\begin{tabular}{|l|l|r|r|r|r|l}
\hline \multicolumn{2}{l|}{ Model } & $\begin{array}{c}\text { Sum of } \\
\text { Squares }\end{array}$ & \multicolumn{1}{c|}{ df } & $\begin{array}{c}\text { Mean } \\
\text { Square }\end{array}$ & F & Sig. \\
\hline \multirow{2}{*}{1} & Regression & 29.163 & 3 & 9.721 & 109.945 & $.000^{\mathrm{b}}$ \\
\cline { 2 - 7 } & Residual & 4.951 & 56 & .088 & & \\
\cline { 2 - 7 } & Total & 34.114 & 59 & & & \\
\hline
\end{tabular}

Sumber: Peneliti 2020

Tabel 5

Koefisien Determinasi Simultan $\left(\mathbf{R}^{2}\right)$

\begin{tabular}{|c|c|c|c|c|}
\hline Model & R & R Square & Adjusted R Square & Std. Error of the Estimate \\
\hline 1 & $.925^{\mathrm{a}}$ & .855 & .847 & .29735 \\
\hline
\end{tabular}

Sumber: Peneliti 2020

\section{Analisa Koefisien Determinasi Simultan $\left(\mathbf{R}^{\mathbf{2}}\right)$}

Berdasarkan data olahan pada tabel 5, nilai RSquare sebesar 0,855. Hal ini menjelaskan bahwa uji koefisien determinasi $\mathrm{R}^{2}$ menunjukan bahwa variabel bebas yaitu lingkungan kerja, stress kerja, dan pengawasan memberikan 85,5\% informasi yang dibutuhkan untuk memprediksi variabel terikat yaitu semangat kerja karyawan dan mempunyai hubungan cukup kuat. 


\section{Tabel 6}

UJI T

\begin{tabular}{|c|c|c|c|c|c|c|}
\hline \multirow{2}{*}{\multicolumn{2}{|c|}{ Model }} & \multicolumn{2}{|c|}{$\begin{array}{l}\text { Unstandardized } \\
\text { Coefficients }\end{array}$} & $\begin{array}{l}\text { Standardized } \\
\text { Coefficients }\end{array}$ & \multirow[t]{2}{*}{$\mathrm{t}$} & \multirow[t]{2}{*}{ Sig. } \\
\hline & & $\mathrm{B}$ & Std. Error & Beta & & \\
\hline \multirow[t]{4}{*}{1} & (Constant) & 1.105 & .274 & & 4.038 & .000 \\
\hline & Lingkungan Kerja (X1) & .621 & .065 & .701 & 9.507 & .000 \\
\hline & Stres Kerja (X2) & -.147 & .046 & -.164 & -3.183 & .002 \\
\hline & Pengawasan (X3) & .240 & .073 & .240 & 3.276 & .002 \\
\hline
\end{tabular}

Sumber: Peneliti 2020

\section{Uji Parsial (Uji t)}

Dari tabel 6 dari variabel lingkungan kerja dapat disimpulkan mengenai uji t (parsial) ditunjukkan dengan hasil perhitungan t hitung yang menunjukkan nilai 9.507. Sedangkan dengan rumus $\mathrm{t}$ tabel $\mathrm{df}=\mathrm{n}-\mathrm{k}=60-4=56 ; \mathrm{t}=0.05 / 2=0,25$ maka diperoleh $\mathrm{t}$ tabel sebesar 2,003 yang berarti t hitung $>\mathrm{t}$ tabel. Untuk uji parsial menggunakan nilai Signifikansi (Sig.) diperoleh nilai Sig. sebesar 0,000 yang berarti dibawah 0,05 (alpha $5 \%$ ). Hal ini berarti variabel lingkungan kerja secara parsial berpengaruh positif terhadap semangat kerja karyawan.

Dari tabel 6 dari variabel stress kerja dapat disimpulkan mengenai uji t (parsial) ditunjukkan dengan hasil perhitungan $t$ hitung yang menunjukkan nilai $-3,183$. Sedangkan dengan rumus $\mathrm{t}$ tabel $\mathrm{df}=\mathrm{n}-\mathrm{k}=60-4=56 ; \mathrm{t}=0.05 / 2=0,25$ maka diperoleh $\mathrm{t}$ tabel sebesar 2,003 yang berarti t hitung $>\mathrm{t}$ tabel. Untuk uji parsial menggunakan nilai Signifikansi (Sig.) diperoleh nilai Sig. sebesar 0,002 yang berarti dibawah 0,05 (alpha $5 \%$ ). Hal ini berarti variabel stres kerja secara parsial berpengaruh negatif terhadap semangat kerja karyawan.

Dari tabel 6 dari variabel pengawasan dapat disimpulkan mengenai uji t (parsial) ditunjukkan dengan hasil perhitungan t hitung yang menunjukkan nilai 3.276. Sedangkan dengan rumus $\mathrm{t}$ tabel $\mathrm{df}=\mathrm{n}-\mathrm{k}=60-4=56 ; \mathrm{t}=0.05 / 2=0,25$ maka diperoleh $\mathrm{t}$ tabel sebesar 2,003yang berarti $\mathrm{t}$ hitung $>\mathrm{t}$ tabel. Untuk uji parsial menggunakan nilai Signifikansi (Sig.) diperoleh nilai Sig. sebesar 0,002 yang berarti dibawah 0,05 (alpha $5 \%$ ). Hal ini berarti variabel pengawasan secara parsial berpengaruh positif terhadap semangat kerja karyawan.

\section{Uji Dominan}

Berdasarkan tabel 6 diperoleh nilai Standardized CoefficientsBetavariabel lingkungan kerja memiliki koefisien beta sebesar 0,701 atau 70,1\%. Variabel stress kerja memiliki koefisien beta sebesar -0,164 atau -16,4\% dan variabel pengawasan memiliki koefisien beta sebesar 0,240 atau 24,0\%. Ini menunjukan bahwa variabel lingkungan kerja memiliki koefisien beta terbesar diantara variabel bebas lainnya yang berarti bahwa variabel lingkungan kerja merupakan variabel yang paling dominan berpengaruh terhadap semangat kerja karyawan sehingga sesuai dengan hipotesis sebelumnya.

\section{SIMPULAN DAN SARAN}

Berdasarkan hasil penelitian dari persamaan regresi linear berganda mengenai pengaruh variabel bebas Lingkungan Kerja (X1), Stres Kerja (X2) dan Pengawasan (X3) terhadap variabel terikat Semangat Kerja (Y), dapat disimpulkan bahwa: a. Variabel Lingkungan 
Kerja (X1), Stres Kerja (X2), Pengawasan (X3) secara simultan berpengaruh signifikan terhadap Semangat Kerja. Hal ini ditunjukan oleh nilai t hitung sebesar 109,945 lebih besar daripada t tabel sebesar 2,76 dengan tingkat signifikan kurang dari 0.05 atau 5\%. b. Variabel Lingkungan Kerja (X1) secara parsial berpengaruh signifikan terhadap Semangat Kerja. Hal ini ditunjukan oleh nilai t hitung sebesar 9.507 lebih besar daripada t tabel sebesar 2,003 dengan nilai signifikan sebesar 0.000 yang berarti kurang dari 0.05 atau 5\%. c. Variabel Stres Kerja (X2) secara parsial berpengaruh signifikan terhadap Semangat Kerja.Hal ini ditunjukan oleh nilai t hitung sebesar -3,183 lebih besar daripada t tabel sebesar 2.003 dengan nilai signifikan sebesar 0,002 yang berarti kurang dari 0.05 atau $5 \%$. d. Variabel Pengawasan (X3) secara parsial berpengaruh signifikan terhadap Semangat Kerja.Hal ini ditunjukan oleh nilai t hitung sebesar 3,276 lebih besar daripada t tabel sebesar 2,003 dengan nilai signifikan sebesar 0,002 yang berarti kurang dari 0.05 atau 5\%. e. Variabel Lingkungan Kerja berpengaruh secara dominan terhadap Semangat Kerja Karyawan, hal ini ditunjukan oleh besarnya nilai 0,701 pada hasil pengujian parsial (uji t) nilai beta tertinggi. Berdasarkan hasil penelitian dan kesimpulan yang telah disajikan maka selanjutnya peneliti menyampaikan saran-saran yang kiranya dapat memberikan manfaat pada pihak-pihak yang terkait atas penelitian ini. Adapun saransaran yang dapat peneliti sampaikan adalah sebagai berikut: a. Perlunya meningkatkan dan memperhatikan perkembangan Lingkungan Kerja, Stres Kerja, Pengawasan pada Semangat Kerja Karyawan CV. Bintang Tex Indonesia, agar karyawan tetap merasa nyaman dan nyaman. b. Untuk meningkatkan Lingkungan Kerja diperlukan dukungan atau kontribusi dari perusahaan dengan menunjang adanya kebersihan, pertukaran udara, dan suara/kebisingan yang lebih ditingkatkan agar karyawan merasa nyaman. Untuk memperhatikan Stres Kerja diperlukan dukungan atau kontribusi dari perusahaan dengan cara tidak memberikan beban kerja yang dirasa terlalu berat, waktu kerja yang mendesak dan iklim kerja yang tidak sehat agar karyawan tidak mengalami stress kerja dan dapat berkonsentrasi dalam bekerja. Untuk meningkatkan Pengawasan diperlukan dukungan atau kontribusi dari perusahaan dengan menunjang adanya tepat waktu, obyektif dan menyeluruh dan terpusat pada titik-titik strategi akan membuat karyawan lebih tertib dan disiplin dalam menyelesaikan tugas. Untuk meningkatkan Semangat Kerja diperlukan dukungan atau kontribusi dari perusahaan dengan menunjang dan memperhatikan rendahnya produktivitas kerja, tingkat absensi yang tinggi, tingkat perpindahan karyawan yang tinggi dan kegelisahan dimana-mana agar karyawandapat menyelesaikan tugas dengan baik dan tepat pada waktunya atau sesuai target. c. Yang berpengaruh dominan terhadap Semangat Kerja Karyawan adalah Lingkungan Kerja sehinngga CV. Bintang Tex Indonesia perlu meningkatkan lingkungan kerja seperti menjaga kebersihan dilingkungan perusahaan, memperhatikan suhu udara diruangan serta karyawan diberikan penutup telinga agar suara mesin-mesin besar tidak mengganggu konsentrasi dalam bekerja.

\section{DAFTAR PUSTAKA}

Busro, Muhammad. 2018. Teori-Teori Manajemen Sumber Daya Manusia. Jakarta: Prenadamedia group. 
Gavinov, Ivan Tinarbudi. Manajemen Perkantoran, 2018. Yogyakarta: Parama Publishing Manusia.

Riinawati. 2019.Pengantar Teori Manajemen Komunikasi dan Organisasi. Yogyakarta: PT. Pustaka Baru.

Sinambela, Lijian Poltak. 2016.Manajemen Sumber Daya Manusia. Jakarta: Bumi Aksara.

Yoyo, Sudaryo. 2018. Manajemen Sumber Daya Manusia, Kopentensi Tidak Langsung Dan Lingkungan Kerja Fisik.Yogyakarta: CV Andi offset. 